\title{
O ENSINO DE HISTÓRIA EM BUSCA DE NOVAS REFERÊNCIAS: Considerações sobre o pensamento de Edgar Morin*
}

\author{
André Wagner Rodrigues ${ }^{1}$
}

Resumo: Esse texto apresenta os resultados de pesquisa bibliográfica que teve como objeto investigar possíveis contribuições do pensamento transdisciplinar de Edgar Morin para as ciências históricas. Acreditamos, depois do estudo realizado, que suas ideias indicam um novo paradigma para se pensar a História enquanto campo de conhecimento e disciplina escolar. É notável sua preocupação em buscar na História referências para fundamentar suas análises em torno dos problemas sociais, políticos, econômicos, culturais, ecológicos, éticos e estéticos que irrompem no tempo presente. Para isso, abordaremos o que muitos estudiosos chamam de "Neo-Humanismo" no pensamento de Morin. Pensamos que suas ideias podem oferecer subsídios para se pensar em propostas curriculares e metodológicas alternativas para o ensino de História, assim como, possibilidades norteadoras de soluções para a reversão dos malefícios orquestrados pelo ritmo informacional e tecnológico da sociedade contemporânea e sua tradição educacional que separa, disjunta e compartimenta os saberes.

Palavras-chave: Ensino de História - Edgar Morin - Transdisciplinaridade

\begin{abstract}
This paper presents the results of literature that had as object to investigate possible contributions of transdisciplinary thought Edgar Morin for the historical sciences. We believe, after study, that their ideas indicate a new paradigm for thinking about history as a field of knowledge and school discipline. It is remarkable in its concern to seek references in history to support their analysis around the social, political, economic, cultural, ecological, ethical and aesthetic that erupts at the present time. To do so, discuss what many scholars call "Neo-Humanism" at the thought of Morin that aims to "see" the present in its complex dimension and, thus, establish links with the past history.
\end{abstract}

Key Words: Teaching History - Edgar Morin - Transdisciplinarity

\footnotetext{
* Artigo submetido em 23 de Outubro de 2012, e aprovado em 27de Dezembro de 2012.

1 É licenciado em História pela UNESP; Pós- Graduado em "Fundamentos de uma Educação para o Pensar" pela PUC de São Paulo. É Mestre em Educação pelo PPGE em Educação da Universidade Nove de Julho, na linha de pesquisa em "Educação e Complexidade". É autor dos livros: "A HISTÓRIA ATRAVÉS DE CONCEITOS: metodologias e práticas de ensino voltadas a uma educação para o pensar" pela editora Andreolli em 2009 e "História, Historiografia e Ensino de História em relação dialógica com a Teoria da Complexidade" pela editora MULTIFOCO em 2011. Leciona na Universidade Bandeirante de São Paulo (UNIBAN/ANHANGUERA), exercendo atualmente a coordenação do curso de licenciatura em História na unidade Campo Limpo. E-mail: andrewunesp@gmail.com
} 
"Podemos, enfim, dizer que a globalização da nação, que se concluiu ao final do século 20 , confere ao planeta uma característica de civilização e cultura comuns; ao mesmo tempo, porém, o fragmenta ainda mais, e a soberania absoluta das Nações cria obstáculos, justamente, ao surgimento da sociedade-mundo. Emancipadora e opressora, a nação torna extremamente difícil a criação de confederações que responderiam às necessidades vitais dos continentes e ainda mais difícil o nascimento de uma confederação planetária."

Edgar Morin. Os problemas do fim do século, p. 134

O que pretendemos nesse artigo é sintetizar algumas importantes considerações teóricas do filósofo francês Edgar Morin, principalmente em relação ao que denomina como "Terra-Pátria"; "cidadania planetária" ou ainda "sociedade-mundo", que insere o ser humano no centro dos dilemas contemporâneos, advogando a favor de um pensamento que busque as relações entre o local e o global, a unidade individual e a pluralidade cultural e o entendimento da tríade indivíduo/sociedade/espécie. Assim, pretendemos identificar em suas contribuições teóricas, alguns subsídios para promover reflexões em torno da criação de propostas metodológicas para o Ensino de História atual.

Antes de iniciarmos esse estudo é importante explicarmos a definição do termo Humanismo, para assim entender se é válido para denominar o pensamento e a produção teórica desse autor. Segundo o dicionário de conceitos históricos, podemos definir o humanismo como:

[...] um empreendimento moral e intelectual que colocava o homem no centro dos estudos e das preocupações espirituais, buscando construir o mais alto tipo de humanidade possível [...] Gerado no contexto das grandes transformações culturais do fim da Idade Média, o Humanismo possui estreitos laços com o Renascimento e com a retomada dos estudos dos clássicos gregos e latinos". (SILVA, 2006, p. 193)

Essa é a definição do "Humanismo clássico" que está distante do NeoHumanismo. Isto porque a proposta dos renascentistas do final do séc. XV e início do XVI que cunharam essa expressão tinham como perspectiva exaltar as potencialidades humanas; as aspirações e conquistas da burguesia em expansão, ou seja, situar o homem no núcleo do cosmos ou no "centro de todas as coisas" (Antropocentrismo). Devemos destacar que estamos nos referindo ao contexto da transição do Feudalismo para o Capitalismo. Dessa forma, é válido destacar esse período como a passagem do 
Teocentrismo cristão para o Antropocentrismo humano, destacadamente um tempo de críticas aos dogmas clericais que prepararam a modernidade para a Reforma Protestante e também para o desenvolvimento científico. Nesse sentido, o Humanismo clássico pode ser pensado como a valorização do egocentrismo e do hedonismo, ou seja, a busca incessante do prazer individual, o que acarreta na exacerbação dos valores individuais ante os coletivos.

Podemos entender como Neo-humanismo uma proposta filosófica e cultural que tende situar os valores humanos no centro dos debates contemporâneos. Isto é, teorizar os principais dilemas do homem e da humanidade do final do século XX e início do século XXI, principalmente aqueles que ameaçam a vida no planeta, notoriamente: os problemas ecológicos, éticos, culturais, sociais e econômicos que irrompem no nosso tempo. Segundo Adalberto Dias de Carvalho, o Neo - Humanismo na obra de Morin busca, sobretudo destacar:

[...] noções-chave como as de autonomia, de Liberdade, de amor, de indivíduo e de sujeito, denunciando aí, por um lado, os equívocos em matéria de fundamentação científica e ideológica, por outro, procurando sempre salvaguardar os valores que lhes são inerentes, tudo isto em prol de uma dignidade do homem potencialmente ameaçada. (1987, p. 33)

O Neo-humanismo se distingue do Humanismo clássico em, pelo menos, três características: primeiramente devemos levar em consideração a distância temporal entre ambas. Essa consideração por si só evidencia contextos sociais, políticos, econômicos e culturais distintos. Em segundo lugar, podemos interpretar o Neohumanismo como a busca da valorização dialógica entre indivíduo/sociedade/espécie, diferentemente do apelo antropocêntrico do humanismo clássico. Em terceiro, devemos destacar que há, nas proposições de Morin, uma tentativa de superação do pensamento clássico, de origem renascentista, de modelo cartesiano, que separa o sujeito do objeto, que disjunta para conceber a unidade, um tipo de pensamento que divide em partes para depois conceber o todo, etc.

Nessas proposições podemos sintetizar três diferenças entre o humanismo clássico e o Neo-humanismo: a distância temporal; as divergências entre Antropo e Sócio-centrismo e as propostas epistemológicas que as fundamentam, deixando claro que o Neo-Humanismo busca uma nova concepção de sujeito que, não pode ser visto de maneira egocentrista ou individualista (como no Humanismo clássico), e sim, em sua 
relação dialógica com a sociedade com que se relaciona e também com a espécie de que faz parte.

A definição de Neo-Humanismo sugere uma nova concepção de ser humano, voltada para a sua inserção no contexto do final do século XX e início do XXI. Um período marcado pelo desenvolvimento ${ }^{2}$ científico, pela especialização técnica, pelo auge da indústria em ritmo acelerado de produção e pelo Capitalismo, sistema que regula as relações econômicas locais, regionais, nacionais e mundiais em sua fase globalizada. ${ }^{3}$ Isso confere ao planeta uma característica de civilização e cultura comuns, mas que ao mesmo tempo, fragmenta e isola, na medida em que a soberania política de algumas Nações e os mandonismos locais e regionais com sua autoridade cega impossibilita a criação de uma confederação planetária. Por esses fatores, Morin argumenta ainda que:

A vida democrática regride. Quanto mais os problemas adquirem uma dimensão técnica, tanto mais escapam às competências dos cidadãos em proveito dos especialistas. Quanto mais os problemas de civilização se tornam políticos, tanto menos os políticos são capazes de integrá-los em sua linguagem e em seus programas. (MORIN, 2005, p. 84)

O desenvolvimento ${ }^{4}$ científico e tecnológico, motor do sistema capitalista, acompanhado das teorias históricas e sociológicas que acreditavam no progresso majestoso da civilização moderna Ocidental $^{5}$, na verdade apresentaram para o século

\footnotetext{
2 A palavra de ordem do progresso capitalista no contexto do final do século $\mathrm{XX}$, talvez seja "Desenvolvimento". Segundo Morin: "O desenvolvimento de nossa civilização produziu maravilhas: a domesticação da energia física, as máquinas industriais cada vez mais automatizadas, as máquinas eletrodomésticas que liberam os lares das tarefas mais escravizadoras, o bem-estar, o conforto, os produtos extremamente variados de consumo, o automóvel (que, como indica seu nome, proporciona a autonomia na mobilidade), o avião, que nos faz devorar o espaço, a televisão, janela aberta para o mundo real e os mundos imaginários..." (Vide seus estudos no livro: "Terra Pátria", p. 83-87)

${ }^{3}$ A Globalização da Economia, como nos sugere Morin: "[...] é cada vez mais um todo interdependente: cada uma de suas partes tornou-se dependente do todo, e, reciprocamente, o todo sofre as perturbações e vicissitudes que afetam as partes. A queda da cotação do café, por exemplo, incita os camponeses da Colômbia a cultivar a coca, que vai alimentar as redes planetárias de transformação e tráfico da droga, e depois a lavagem do dinheiro em bancos de países como a Suiça [...]" (Vide estudos de Morin, no livro Terra Pátria, p. 34)

${ }^{4}$ Podemos entender esses reflexos do desenvolvimento do Capitalismo inclusive no Brasil. Segundo Morin: A noção de desenvolvimento hoje corrente pode ser devastadora para os índios - e não apenas para eles, mas para toda a humanidade, considerando que a integração dos índios à sociedade não pode significar a desintegração da cultura indígena. Isso pode trazer consequências graves, como a degradação da floresta pelo uso de pesticidas nos projetos agrícolas dos latifundiários. Claro, há também a questão urbana e a favelização das cidades, tão grave como o crescimento do número de carros em circulação. (Ver entrevista de Morin na íntegra para o Estado de São Paulo em 02/08/2009)

${ }^{5}$ Nas palavras de Morin, o Ocidente sofre ainda e cada vez mais: "do domínio do calculo, da técnica do lucro sobre todos os aspectos da vida humana, do domínio da quantidade sobre a qualidade, da 
XX: a barbárie e os resultados catastróficos de duas guerras Mundiais; a escalada dos partidos nazi-fascistas ao poder; o colapso do Capitalismo Mundial; a bipolaridade de dois sistemas ideológicos, políticos e econômicos que colocaram em risco o destino da humanidade; a desigualdade social em escala mundial; o xenofobismo; a miséria; a fome, etc. E mais:

O desenvolvimento, do modo que é concebido, ignora aquilo que não é calculável nem mensurável: a vida, o sofrimento, a alegria, o amor, e o único critério pelo qual mede a satisfação é o crescimento (da produção, da produtividade, da receita monetária). Definido unicamente em termos quantitativos, ele ignora as qualidades: de existência, de solidariedade, do próprio meio e também a qualidade de vida. (MORIN, 1991, p. 117)

Por causa dos avanços tecnológicos e científicos de finais desse período em consequiência do consumo exacerbado, combustível do próprio sistema capitalista, novos dilemas colocaram o destino do planeta e da humanidade no centro das discussões políticas em escala Mundial. Muitas conferências ecológicas, que propunham a redução da emissão de monóxido e dióxido de carbono na atmosfera, promoveram divergências entre as Nações. A Organização das Nações Unidas, de tempos em tempos, promove grandes arrecadações para países que apresentam condições de miséria absoluta, de grande parcela de sua população convivendo com epidemias e extremas desigualdades sociais. Mas apesar do esforço da ONU, e de várias Instituições e ONG's que atuam em caráter regional ou Nacional, os problemas persistem.

Em face de todas essas considerações é importante perguntarmos se a Teoria da Complexidade $^{6}$ de Edgar Morin aponta caminhos para superarmos, ou ao menos,

degradação da qualidade de vida nas megalópoles e da desertificação da zona rural, utilizada pela agricultura e a pecuária industriais que já produziram várias catástrofes alimentares. (vide estudos sobre essa temática, no livro "Os problemas do fim do século", p. 93-101)

6 A expressão "complexidade" pode soar como complicada, intrincada ou até mesmo difícil. Morin não emprega este termo nesta conotação; ele o emprega no sentido originário do latim complexus que é entendido como aquilo que é tecido em conjunto. Esta teoria foi herdada dos estudos de Morin sobre a Teoria dos Sistemas, da Comunicação e da Cibernética. A teoria da Complexidade propõe que há na realidade como um todo e, também no acontecer histórico, um tecido interdependente, antagônico e ao mesmo tempo complementar. Assim, estão relacionados entre si o todo e as partes, as partes e o todo, as partes entre si e as relações das partes entre si com o todo. Assim, também, na História: as ações individuais; os acontecimentos; as transformações sociais, políticas, econômicas, culturais; o acaso e a incerteza, etc., estão relacionados intrinsecamente entre si, complementarmente e antagonicamente e, produzem desta forma, as transformações históricas no curso do tempo. A complexidade da realidade, ou a sua trama, organiza-se, desorganiza-se e reorganiza-se, constituindo-se de acordo com princípios que a operam, diz Morin. Assim, também a história humana. 
compreendermos a nossa parcela de responsabilidade na perspectiva de transformar o planeta em que vivemos. Indica Morin que:

"[...] a missão da educação para a era planetária é fortalecer as condições de possibilidades de emergência de uma sociedade-mundo composta por cidadãos protagonistas, conscientes e criticamente comprometido com a construção de uma civilização planetária" (2003, p. 98)

A proposta educacional, presente em sua teoria pode ensejar caminhos para se pensar em possibilidades metodológicas alternativas para o Ensino de História, como disciplina que pode promover debates e reflexões que levem as novas gerações de alunos, a reconhecerem a sua parcela de contribuição no agravamento de todos esses problemas, e principalmente no amadurecimento de uma consciência e da responsabilidade necessária para uma postura voltada para a transformação necessária do nosso planeta. Tentaremos situar as contribuições educacionais de Edgar Morin nesse sentido.

Para ele é necessário que se dê aos alunos e adolescentes que irão enfrentar o mundo do terceiro milênio um tipo de pensamento ${ }^{7}$ e cultura que possa prepará-los para "articular, religar, contextualizar, situar-se no contexto e, se possível, globalizar, reunir os conhecimentos que adquiram" (2002, p. 29). Entende ainda que no interior do espaço escolar, as disciplinas devem colaborar para que tais questões estejam presentes, sendo importante somar a isso a possibilidade da realização de jornadas temáticas, cada uma delas centradas sobre um grande tema que permita religar as disciplinas. Jornadas temáticas que ressaltem a importância de discutir: "o mundo, a terra, a vida, a humanidade, literatura, poesia, línguas, artes, cinema, culturas adolescentes, conhecimento" (Idem, p. 35). Para que esse tipo de educação aconteça, nossa tradição escolar precisa transformar-se em uma forma de organização $\operatorname{transdisciplinar~}^{8} \mathrm{e}$ complexa, capaz de produzir conhecimentos pertinentes, onde docentes e discentes

\footnotetext{
${ }^{7}$ Cabe agora ressaltar, que em algumas obras Morin, sugere: “[...] a busca sobre a compreensão do mundo, do humano e da humanidade tendo como base os códigos de um conhecimento complexo, pois este tem a pretensão de conceber, inseparavelmente, a dialógica da unidade e da diversidade humana" (Vide estudos de Morin no livro "Introdução ao pensamento Complexo, p. 76). Essa consideração pode indicar sua preocupação Neo-humanista.

${ }^{8}$ Trans, significa través de. Isto é, pensar a disciplina escolar como campo do saber autônomo, que possa atravessar os seus limites de conhecimento e atuação. Uma disciplina "aberta" está disposta a ampliar os assuntos e temáticas comuns ao cotidiano escolar. Nossa tradição de ensino compartimentou o conhecimento em áreas específicas do saber, por isso, os professores ainda são resistentes a promoverem um debate que possa ser direcionado a uma transformação de sua disciplina. Mas as próprias necessidades do mundo contemporâneo, aos poucos, nos mobilizam para pensar em propostas emergenciais de transformação do currículo escolar.
} 
aprendam a se situar e a se compreender no universo onde convivem e atuam para poderem construir uma identidade individual, regional, da sociedade que representa e também da espécie, num mundo com características comuns e problemas que também devem ser compartilhados. A solidariedade deve ser uma característica desse aluno do terceiro milênio. Isso pode ser dificultado pelo tipo de educação que temos, pois,

nossa educação nos ensinou a separar, compartimentar, isolar, e não a ligar os conhecimentos, e portanto nos faz conceber nossa humanidade de forma insular, fora do cosmos que nos cerca e da matéria fisica com que somos constituidos" (MORIN, 2000, p. 48)

Além de defender a aquisição de uma identidade planetária, devemos acrescentar que um dos maiores desafios da Educação e do Ensino de História seja trabalhar de maneira eficiente os temas ligados à diversidade ou pluralidade cultural no contexto de sala de aula. Mesmo sendo temática corrente e obrigatória nos PCN’s de História e Geografia, visualizamos poucos trabalhos nessa direção. Os poucos que ocorrem servem para ilustrar algumas datas, tais como: O dia do Índio ou o dia da Consciência Negra. Dessa forma, gradativamente os alunos ficam com uma referência parcelada ou incompleta do reconhecimento de suas origens. Conhecer a identidade terrena, cósmica e planetária é indispensável ao ser humano e é proposta condizente com o novo Humanismo.

As ideias de identidade e de diversidade nas obras de Morin são conhecidas por um bom número de educadores e estudiosos, assim como sua visão do ser humano. Este é concebido, por ele, biológica e culturalmente na perspectiva dialógica "indivíduo, sociedade e espécie". A identidade é resultante, também, do envolvimento e reconhecimento do ser humano em seu grupo de convívio, como parte integrante da cultura de seu tempo e de uma relação com e compreensão dos seus antepassados. Esse entendimento está presente nos objetivos dos Parâmetros Curriculares Nacionais de História e Geografia, que apontam para a necessidade de ensinar aos alunos sua história local, regional, nacional, mundial e planetária, reforçando que isso é importante para a constituição da identidade dos alunos do Ensino fundamental e Médio o:

Levantamento de diferenças e semelhanças individuais, sociais, econômicas e culturais entre os alunos da classe e entre eles $e$ as demais pessoas que convivem e trabalham na escola: idade, sexo, origem, costumes, trabalho, religião, etnia, organização familiar, lazer, jogos [...] (PCN's de História e Geografia, 2000, p. 54)

Além de: 
"[...] Identificar as ascendências e descendências das pessoas que pertencem à sua localidade, quanto à nacionalidade, etnia, língua, religião e costumes, contextualizando seus deslocamentos $e$ confrontos culturais e étnicos, em diversos momentos históricos nacionais [...]" (PCN's de História e Geografia, 2000, p. 62)

Porém, notamos ainda nas leituras de livros didáticos de História e nas aulas em várias escolas de São Paulo ${ }^{9}$ uma maneira de apontar os sujeitos e suas identidades como seres desvinculados de suas relações culturais, quase como supra-humanos, destacando-os como os verdadeiros "construtores do passado" os grandes líderes nacionais, reis, príncipes, estadistas, etc. Além disso, eles não são considerados subjetivamente, isto é, como portadores de emoções, sentimentos e até defeitos, de acordo com certos critérios de análise. Isso pode levar o aluno a não se identificar com o seu passado, que parece não existir, obscurecido por "personalidades" que parecem extemporâneas e nem com o estudo desse passado, pois não se reconhece como partícipe do processo de transformações históricas. O resultado mais drástico desse tipo de ensino é o não reconhecimento identitário da juventude. Em face disso, a construção da identidade desses estudantes fica de alguma forma comprometida nas aulas de História.

Outra reflexão importante a respeito da construção da identidade juvenil é o estudo sobre a origem de Nação e do povo brasileiro. Acostumamo-nos com um tipo de ensino que inaugura a História do Brasil a partir da chegada dos colonizadores portugueses. Em cursos de licenciatura em História, dividimos a História do Brasil em: Colônia, Império e República. Isto quer dizer, que também na academia, ainda constatamos esse modelo de ensino. O Brasil se constitui como civilização após o seu “descobrimento". Há uma pergunta que muitos jovens do ensino fundamental e médio fazem aos seus professores de História: Não havia História do Brasil antes da chegada dos portugueses? As populações indígenas não tinham história? Os índios não fazem parte da civilização? Questões que ficam muitas vezes sem respostas e logicamente contribuem para uma visão estereotipada de identidade. Os objetivos dos Parâmetros curriculares Nacionais reforçam que é importante uma nova visão dos estudos históricos e que também é necessária, para os alunos do Ensino fundamental e Médio, a

\footnotetext{
${ }^{9}$ Realizamos esse estudo com alunos (futuros professores de História) do curso de licenciatura em História da Universidade Bandeirante de São Paulo (UNIBAN) no período de 2007-2009. Desse resultado, produzimos um livro intitulado: "História através de conceitos: metodologias e práticas de ensino voltados a uma educação para o pensar", citado na bibliografia. 
compreensão das origens e da diversidade étnica, da formação do povo brasileiro. Daí a proposta de presença nas aulas de História de:

\begin{abstract}
“[...] Identificação do grupo indígena da região e estudo do seu modo de vida social, econômico, cultural, político, religioso e artístico [...] o território que habitam e que já habitaram; organização das famílias e parentesco, a produção e distribuição de alimentos, a divisão de trabalho entre os sexos e as idades, as moradias e a organização do espaço, os rituais culturais e religiosos, as relações materiais e simbólicas com a natureza, a língua falada, a vestimentas, os hábitos cotidianos de higiene [...]" (PCN's de História e Geografia, 2000, p. 55 e 56$)$
\end{abstract}

Questões relacionadas à formação da identidade brasileira devem se constituir em temática importante nas aulas de História. É possível que o conhecimento do passado ganhe interesse maior se os programas curriculares apresentarem uma trajetória histórica sobre a constituição do povo brasileiro, tentando resgatar a cultura produzida pelas civilizações indígenas em tempos anteriores à colonização e suas influências presentes até hoje em nossa cultura. Além disso, provavelmente oferecesse uma compreensão maior sobre a identidade de povo brasileiro.

Entre os principais valores que a Escola deve promover e cultivar no terceiro milênio está o respeito à diferença, que pode ser pensado como a aceitação da pluralidade cultural e étnica, assim como a realização do diálogo e do debate de ideias. Uma escola que esteja aberta para a novidade e criatividade que as novas gerações, a cada ano, de maneira mais desafiadora trazem consigo. Uma postura contestadora pode ensejar transformações curriculares, metodológicas e de objetivos educacionais.

\title{
Referências Bibliográficas
}

ALMEIDA, Cleide. e PETRAGLIA, Isabel (orgs.). Estudos de Complexidade. São Paulo: Xamã, 2006. BITTENCOURT, Circe Maria Fernandes. Ensino de História: fundamentos e métodos. São Paulo: Cortez, 2004.

.(org.) O saber Histórico na sala de aula. 11. ed. São Paulo: Contexto, 2006.

CARVAlHO, Adalberto Dias de. Morin e a Renovação do Humanismo. Revista de Ciências, Letras e Filosofia da Universidade do Porto. Lisboa: 1987.

MORIN, Edgar. A cabeça bem feita: repensar a reforma, reformar o pensamento. Rio de Janeiro: Bertrand Brasil, 1999. 2007.

Cultura e barbárie européias. Tradução de Daniela Cerdeira. Rio de Janeiro: Bertrand Brasil,

Os sete saberes necessários à Educação do futuro. São Paulo: Cortez, 2000.

MORIN, Edgar e KERN, Anne Brigitte. Terra Pátria. Tradução de Paulo Neves. Porto Alegre: Sulina, 2005.

MORIN, Edgar, BOCCHI, Gianluca e CERUTTI, Mauro. Os problemas do fim do século. Tradução de Cascais Franco. Lisboa: Editorial Notícias, 1991.

MORIN, Edgar, CIURANA, Emilio Roger e MOTTA, Raul Domingo. Educar na era planetária: O pensamento complexo como método de aprendizagem pelo erro e incerteza humana. Tradução de Sandra Trabucco Valenzuela. $3^{\circ}$ Ed. São Paulo: Cortez, 2009. 
RODRIGUES, André Wagner. A História através de conceitos: metodologias e práticas de ensino voltadas a uma Educação para o pensar. São Paulo: Andreolli, 2009.

História, historiografia e ensino de História em relação dialógica com a Teoria da Complexidade. Rio de Janeiro: Multifoco, 2011 